\title{
Characterization of Populations of Rhizoctonia solani in Paddy Rice Fields in Côte d'Ivoire
}

\author{
S. Banniza, A. A. Sy, P. D. Bridge, S. A. Simons, and M. Holderness
}

First author: Crop Development Centre, University of Saskatchewan, Saskatoon SK, Canada S7N 5A8; second author: International Institute of Tropical Agriculture, BP 08-0932, Cotonou, Republic of Benin; third and fifth authors: CABI Bioscience, Bakeham Lane, Egham,

Surrey TW20 9TY, United Kingdom; and fourth author: CABI Africa Regional Centre, Village Market, Nairobi, Kenya. Accepted for publication 14 January 1999.

\begin{abstract}
Banniza, S., Sy, A. A., Bridge, P. D., Simons, S. A., and Holderness, M. 1999. Characterization of populations of Rhizoctonia solani in paddy rice fields in Côte d'Ivoire. Phytopathology 89:414-420.

Isolates of Rhizoctonia solani were obtained from plant and soil samples that had been systematically collected in a field experiment in Côte d'Ivoire to study the diversity of the pathogen and the influence of three different rice rotations on the pathogen population. Characterization by morphology, anastomosis testing, pathogenicity testing, and restriction fragment length polymorphisms (RFLPs) of AT-rich DNA (AT-DNA) showed that there were no differences in isolates from different experimental plots, suggesting that the soil as well as the plant population of the fungus was indistinguishable throughout the experiment and was not influenced by

crop rotation. Analysis of AT-DNA showed that the isolates obtained from plant material and one from soil shared a distinct banding pattern, identical with the AT-DNA RFLP obtained for the reference strain of anastomosis group 1 (AG-1). The remaining soil isolates produced a consistent RFLP pattern that was distinct from that of the plant isolates. Morphological characterization of isolates produced two major clusters consisting of the same groups of isolates as found by AT-DNA RFLP. Diversity in morphological characters was much higher in plant than in soil isolates and indicated that the population might consist of several clones. Anastomosis testing revealed that soil as well as plant isolates were able to fuse with the tester strain of AG-1. Significant differences in disease severity were observed between the two groups of isolates in pathogenicity tests on rice plants, with plant isolates being distinctively more virulent.
\end{abstract}

Rhizoctonia solani (teleomorph: Thanatephorus cucumeris) is the causal agent of rice sheath blight, which has become a major constraint to rice production during the last 2 decades (20). The emergence of $R$. solani as an economically important rice pathogen has been attributed to the intensification of rice-cropping systems with the development of new short-statured, high-tillering, highyielding varieties, high plant densities, and an increase in nitrogen fertilization $(12,33)$. These factors promote disease spread by providing a favorable microclimate, due to a denser leaf canopy with an increased leaf-to-leaf and leaf-to-sheath contact (37).

Among the 12 anastomosis groups (AG) that have been described in $R$. solani to date (5), isolates of AG-1 IA have been associated with the rice sheath blight pathogen $(12,33)$. Diversity within rice sheath blight isolates has been studied by morphological characterization $(40,47)$ and pathogenicity testing $(1,17)$, and by studying intra- and extracellular enzymes and proteins $(22,25$, $54)$, cellular fatty acids $(15,16)$, and various molecular techniques $(13,21,22,48)$. Although earlier studies suggested that AG-1 IA represented a homogeneous group of isolates (21), recent investigations support the hypothesis that the sheath blight pathogen is far more diverse than previously assumed $(22,48)$. Knowledge of field populations of this pathogen is still scarce, particularly in tropical agroecosystems, and to date only one detailed study of field populations has been published (31). However, understanding of disease epidemiology and host-pathogen interactions is greatly dependent on knowledge of the diversity of the pathogen at the field level.

The objective of this study was to characterize isolates of $R$. solani in paddy rice plots by morphological characterization, pathogenicity testing, and anastomosis testing in conjunction with mo-

Corresponding author: S. Banniza; E-mail address: Banniza@skyway.usask.ca

Publication no. P-1999-0309-01R

(C) 1999 The American Phytopathological Society lecular markers obtained from AT-rich DNA (AT-DNA) restriction fragment length polymorphisms (RFLPs). Characters obtained from these approaches were used to study the influence of three different rice rotations on the structure of populations of the pathogen in experimental plots.

\section{MATERIALS AND METHODS}

Field site. Soil and plant samples were collected in nine irrigated paddy rice research plots $(2.5 \times 16 \mathrm{~m}$ each $)$ of the Institute des Savannes, Bouaké, Côte d'Ivoire, that had a long history of sheath blight occurrence. Three different rice rotations (three successive rice crops, a rice-soybean-rice rotation, and a rice-weed fallow-rice rotation) were planted in three replicates (blocks) from April 1994 until July 1995. Rice seed samples were checked for $R$. solani infection prior to planting and were found to be free of the disease. Plots within each block were separated by paddy dikes, and blocks were separated by drainage canals. Due to possible water influx from drainage canals and plots grown with paddy rice, the layout of the experiment was restricted in that soybeans were not planted in the plots adjacent to the canals or rice plots. Soil and plant material was sampled along diagonal transects within the plots with 20 equidistant sampling points. For soil samples, a volume of approximately 1.5 liters of the upper $10-\mathrm{cm}$ soil layer at each sampling point was transferred into plastic bags. Plant samples of each sampling point were stored in separate paper bags until isolation to avoid cross-contamination. Soil samples were collected prior to the first rice crop for each rotation, and again prior to the second rice crop, soybean crop, and weed fallow, respectively. A third set was removed prior to harvest of the last rice crop in all plots. Plant samples were collected prior to harvest of the first rice crop and prior to harvest of the last rice crop.

Isolation from plant and soil material and storage of isolates. $R$. solani was isolated from soil samples of the first and last 
collections. Infection by Rhizoctonia spp. was not observed on weed plants in the weed fallow or on soybean plants (data not shown). Plant tissue of rice sheath and leaves with sheath blight symptoms was surface-sterilized in a $2 \%$ dilution of sodium hypochlorite solution (14\% available chlorine, wt/vol) and placed on tap water agar (TWA). Hyphal tips from mycelia with morphological characteristics typical of Rhizoctonia spp.-like fungi were subcultured onto potato dextrose agar (PDA). These isolates are subsequently referred to as "plant isolates." Soil samples were separated into organic and inorganic fractions by wet sieving using a method similar to that of Weinhold (50). Soil samples were suspended in tap water, and the suspension was screened through a $425-\mu \mathrm{m}$ sieve. The material on the sieve was resuspended into tap water and allowed to settle before the floating material was decanted onto the $425-\mu \mathrm{m}$ sieve. The remaining soil particles were resuspended in tap water four more times until no more floating material was apparent. After each suspension, followed by a brief settling period, the floating debris was decanted onto the screen. The organic material on the sieve was then air-dried at room temperature.

No sclerotia could be detected in this material in a preliminary study; therefore, single particles of the organic matter ( $425 \mu \mathrm{m}$ to $2 \mathrm{~mm}$ ) were plated out on TWA petri dishes amended with antibiotics $(0.024 \%$ benzylpenicillin [sodium salt] and 0.2 ppm of streptomycin sesquisulfate). Further isolation procedures for Rhizoctonia spp.-like fungi were as described above and the isolates subsequently referred to as "soil isolates." To test this soil isolation method for any possible bias toward a certain fraction of the population of $R$. solani, rice plants were inoculated with soil isolates and with plant isolates. Infected rice material with symptoms was buried in moist soil and incubated for 1 week. Subsequent isolation from material inoculated with both types of isolates showed that plant isolates were as readily isolated from the soil as were soil isolates, indicating that no selection occurred through the isolation procedure. For long-term storage in the culture collection of CABI Bioscience, isolates were grown in deep one-quarter-strength PDA culture in Universal tubes (Fisher Scientific UK, Loughborough, United Kingdom) and covered with sterile mineral oil.

A set of 40 isolates of $R$. solani was selected from the 172 isolates obtained, ensuring that isolates were represented from a wide range of sampling points in all plots and from all sets of soil and plant samples collected during the experiment. This subset was used for subsequent characterization of isolates. In all, 18 isolates were obtained from soil samples ('S') and 22 from plant samples ('P'). In addition to the 40 field isolates, the reference strain for AG-1 IA, IMI 303152 (Ogoshi CS-2), was also included.

Morphological characterization. Isolates of $R$. solani were subcultured onto PDA petri dishes in triplicate and incubated at $25^{\circ} \mathrm{C}$ for 4 weeks. A total of 30 morphological characters based on colony color, character of mycelium, and color, size, and position of sclerotia were recorded for each isolate. The resulting data matrix was analyzed by unweighted pair group analysis (UPGMA) in the program Multi-Variate Statistical Package Plus (version 2.0; Kovach Computing Services, Pantraeth, Anglesey, Wales, United Kingdom) using Gower's coefficient that allows binary, multistate, and quantitative variables to be analyzed in the same data set. The resulting dendrogram was supported by calculating the cophenetic correlation coefficient (CCC) (Microsoft Excel 97; Microsoft Corp., Redmond, WA), which is a measure of the agreement between the similarity values implied by the dendrogram and those of the original similarity matrix (41).

DNA extraction. Isolates were grown in a glucose yeast medium ( $1.0 \mathrm{~g}$ of $\mathrm{NH}_{4} \mathrm{H}_{2} \mathrm{PO}_{4}, 0.2 \mathrm{~g}$ of $\mathrm{KCl}, 0.2 \mathrm{~g}$ of $\mathrm{MgSO}_{4} \cdot 7 \mathrm{H}_{2} \mathrm{O}$, $10.0 \mathrm{~g}$ of glucose, $5.0 \mathrm{~g}$ of yeast extract, $1.0 \mathrm{ml}$ of $0.5 \%$ [wt/vol] copper solution, and $1.0 \mathrm{ml}$ of $1 \%$ [wt/vol] zinc solution per liter of distilled water) for 4 days at $27^{\circ} \mathrm{C}$ in an orbital incubator (Gallenkamp, Crawley, United Kingdom) at $100 \mathrm{rpm}$. Cultures were harvested aseptically by vacuum filtration, washed with sterile dis- tilled water, and freeze-dried. The procedure for extracting DNA from isolates of $R$. solani was adapted from the methods described by Raeder and Broda (35) and Vilgalys and Hester (49): lyophilized mycelium was ground and approximately $50 \mathrm{mg}$ was homogenized with $500 \mu \mathrm{l}$ of extraction buffer $(0.15 \mathrm{M} \mathrm{NaCl}, 50 \mathrm{mM}$ Tris$\mathrm{HCl}, 10 \mathrm{mM}$ EDTA, and $2 \%$ sodium dodecyl sulfate, $\mathrm{pH} 8$ ). The slurry was incubated at $65^{\circ} \mathrm{C}$ for $30 \mathrm{~min}$ prior to the addition of $500 \mu \mathrm{l}$ of phenol chloroform isoamyl alcohol and centrifugation at $13,000 \times g$ at $4^{\circ} \mathrm{C}$ for $1 \mathrm{~h}$. The upper aqueous layer was collected and incubated with $25 \mu \mathrm{l}$ of ribonuclease solution $(20 \mathrm{mg}$ of ribonuclease A [70 U/mg] per $\mathrm{ml}$ of Tris-EDTA buffer [TE; $10 \mathrm{mM}$ Tris- $\mathrm{HCl}$ and $1 \mathrm{mM}$ EDTA]) for $10 \mathrm{~min}$. An equal volume of chloroform/isoamyl alcohol (24:1, vol/vol) was added, followed by centrifugation at $13,000 \times g$ at $4^{\circ} \mathrm{C}$ for $10 \mathrm{~min}$. The upper aqueous layer was collected, and DNA was precipitated with 0.54 volume of cold isopropanol. Pellets of DNA were washed in $70 \%$ ethanol, dried under vacuum, and finally redissolved in 10 to $50 \mu \mathrm{l}$ of TE buffer, depending on the size of the pellet. Dissolved DNA was stored at $-20^{\circ} \mathrm{C}$.

RFLP analysis of AT-DNA. RFLPs of AT-DNA were generated by digestion of total DNA with HaeIII. This enzyme digests nuclear DNA to fragments less than $1 \mathrm{~kb}$, whereas AT-DNA is cut less frequently, resulting in discrete large molecular weight bands (11). DNA fragments obtained in this way have been presumed to be mitochondrial in a number of genera $(11,45,52)$ and were proven to be so in Fusarium oxysporum, Verticillium lecanii, and Metarhizium anisopliae $(23,46)$. Although not the rule in all fungi (44) and not yet studied in $R$. solani, the inheritance of mitochondrial DNA has been demonstrated to be uniparental in many fungi (10, $14,24,27,43,51)$. While providing sufficient RFLPs at species and subspecies levels to allow the study of populations (9), uniparental inheritance is of particular interest in multinuclear fungi like $R$. solani in which the origin of nuclei is unknown.

A total of 8 to $15 \mu \mathrm{l}$ of dissolved DNA of each isolate was di-

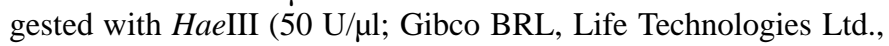
Paisley, United Kingdom) according to the manufacturer's instructions. Restriction fragments were separated on a $1 \%$ agarose gel in Tris-acetate-EDTA (4.84 g of Tris-base, $2.71 \mathrm{~g}$ of sodium acetate trihydrate, and $0.38 \mathrm{~g}$ of EDTA per liter of distilled water) at $6 \mathrm{~V} \mathrm{~cm}^{-1}$ and stained with ethidium bromide. Banding patterns of isolates were compared and characteristic fragments identified. The presence or absence of each fragment was scored for all isolates. Similarities were determined from Gower's coefficient that, when used with binary data, is identical to the simple matching coefficient. Clustering was by UPGMA, and the CCC was calculated as before.

Anastomosis grouping. Anastomosis grouping was conducted for a representative set of 10 isolates on clean slides in petri dishes that served as moisture chambers. Slides were dipped into ethanol, flamed, and placed on top of two pieces of TWA that acted as "piers." Two thin plugs of TWA (5-mm diameter) were arranged on the slide $2 \mathrm{~cm}$ apart. Sclerotia of IMI303152 and the isolate to be tested were placed on each of the agar plugs. If isolates did not produce sclerotia, thin plugs of growing cultures were used instead. Before sealing the petri dishes, $5 \mathrm{ml}$ of sterile distilled water was added to each dish. Petri dishes were incubated at $25^{\circ} \mathrm{C}$, and growth was monitored every $24 \mathrm{~h}$. As soon as hyphae of the two isolates made contact, slides were removed from the petri dish, stained with lactophenol cotton blue $(0.1 \%)$, and examined under the microscope. At least two slides were prepared for each isolate under investigation. Anastomosis was determined at $\times 400$ and fusion confirmed at $\times 1,000$ magnification.

Pathogenicity testing. Pathogenicity testing was conducted in the glasshouse of CABI Bioscience, United Kingdom Centre Egham, on Oryza sativa cv. IR64. Prior to testing, all isolates were passed through rice and reisolated. Rice plants were inoculated 4 weeks (experiment 1) and 13 weeks (experiment 2) after planting, with inoculum consisting of millet grains that had been sterilized, soaked in sterile distilled water, and inoculated with isolates of $R$. solani. 
After an incubation period of 4 days, 10 colonized millet grains were placed on the soil surface adjacent to the sheath of the rice plant. For each isolate, five replicate rice plants were inoculated in a completely randomized experimental design. Plants were kept at 24 to $30^{\circ} \mathrm{C}$ and were kept wet through overhead irrigation. Dis-

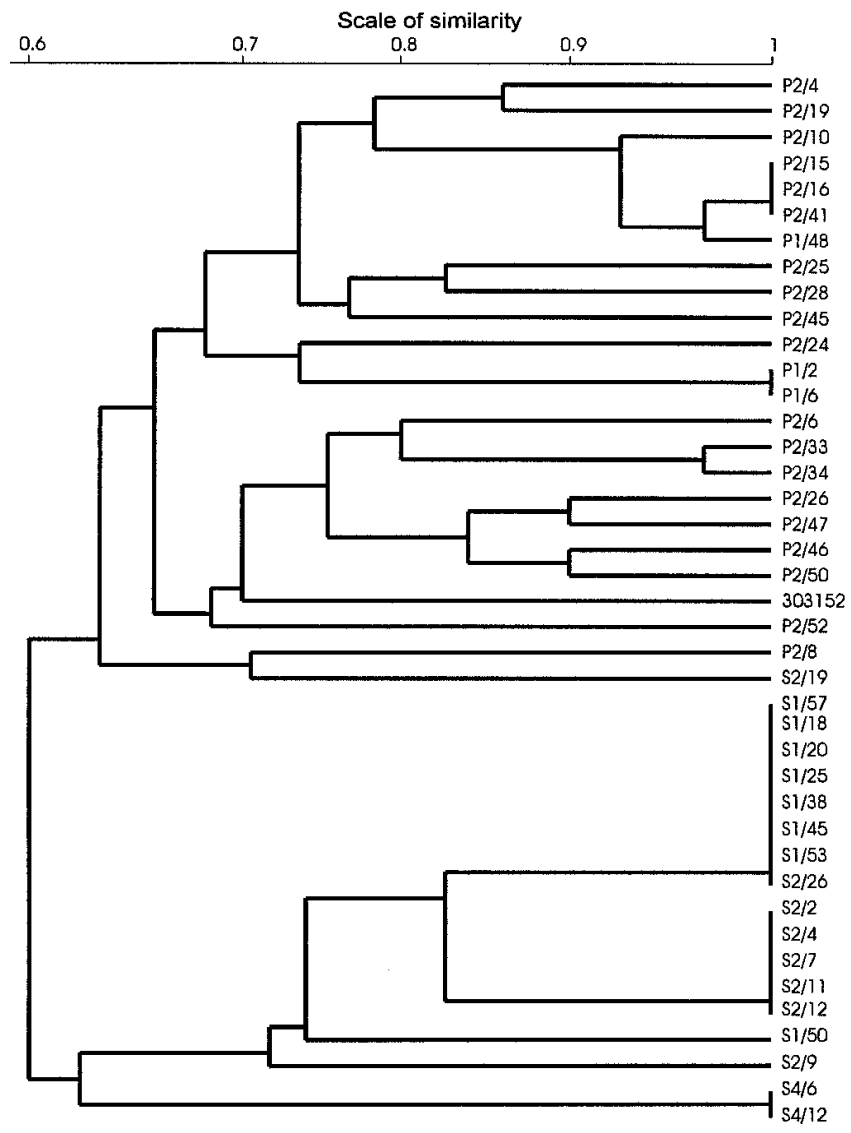

Fig. 1. Dendrogram depicting morphological similarities of isolates of Rhizoctonia solani from a field experiment in Côte d'Ivoire. Isolates coded 'P' were obtained from soil material and those coded ' $\mathrm{S}$ ' originated from soil material. Distance and similarity analysis based on Gower's coefficient, unweighted pair group analysis clustering, cophenetic correlation coefficient $=0.87$.

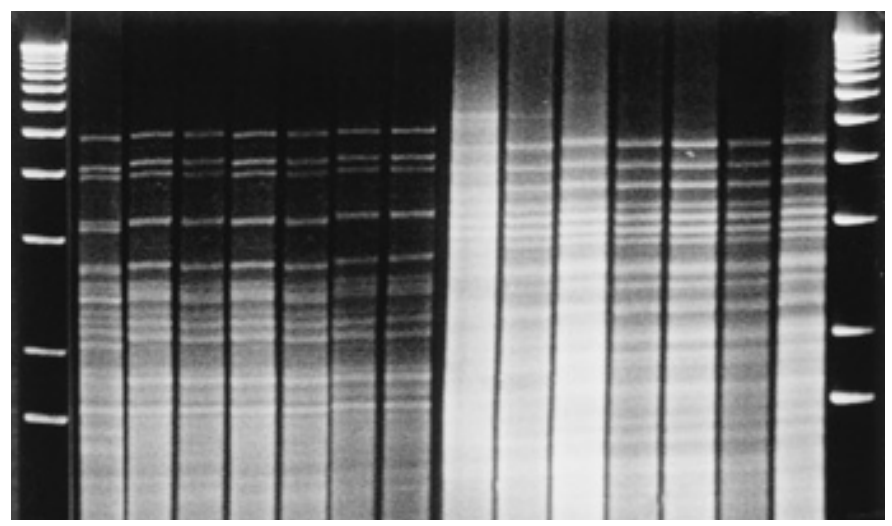

Fig. 2. AT-rich DNA restriction fragment length polymorphisms for isolates of Rhizoctonia solani from a field experiment in Côte d'Ivoire (HaeIII digest). From left to right: kilobase $(\mathrm{kb})$ marker, P2/8, P2/7, P1/48, P2/10, P2/16, $\mathrm{P} 2 / 33, \mathrm{P} 2 / 47, \mathrm{~S} 1 / 38, \mathrm{~S} 1 / 50, \mathrm{~S} 1 / 53, \mathrm{~S} 2 / 2, \mathrm{~S} 2 / 11, \mathrm{~S} 2 / 26, \mathrm{~S} 4 / 6$, and kb marker. Isolates coded ' $\mathrm{P}$ ' were obtained from plant material and those coded ' $\mathrm{S}$ ' originated from soil material. ease severity was recorded 2 weeks after inoculation in experiment 1 and 3 weeks after inoculation in experiment 2 by measuring the distance from soil level to the top of the highest lesion (top lesion height). Isolate identities were confirmed through reisolation. Data were not normally distributed; therefore, an analysis of variance by ranks using the Kruskall-Wallis test in the package SPSS (release 6.0/93; SPSS Inc., Chicago) was conducted, followed by a nonparametric multiple comparison using the Nemenyi test (30). Differences in means of plant isolates and soil isolates were tested by an independent-samples $t$ test in the same package. Disease symptoms were further investigated on detached rice leaves inoculated with isolates of $R$. solani. Rice leaves were cut into pieces of 7 to $8 \mathrm{~cm}$ in length, placed in petri dishes lined with sterile moist filter paper, and inoculated with 2 -mm plugs of the isolates. Each isolate was inoculated onto four pieces of rice leaf. Petri dishes were sealed and incubated for 7 days at room temperature. Symptoms were described after 1 week.

\section{RESULTS}

Morphological characterization. Isolates of $R$. solani from the field experiment in Côte d'Ivoire fell into two major morphological groups, seen in the dendrogram as two distinct clusters $(\mathrm{CCC}=$ 0.87) (Fig. 1). The first cluster consisted mainly of plant isolates, with the exception of one soil isolate, and was characterized by a cream to dark brown colony pigmentation and dark brown sclerotia

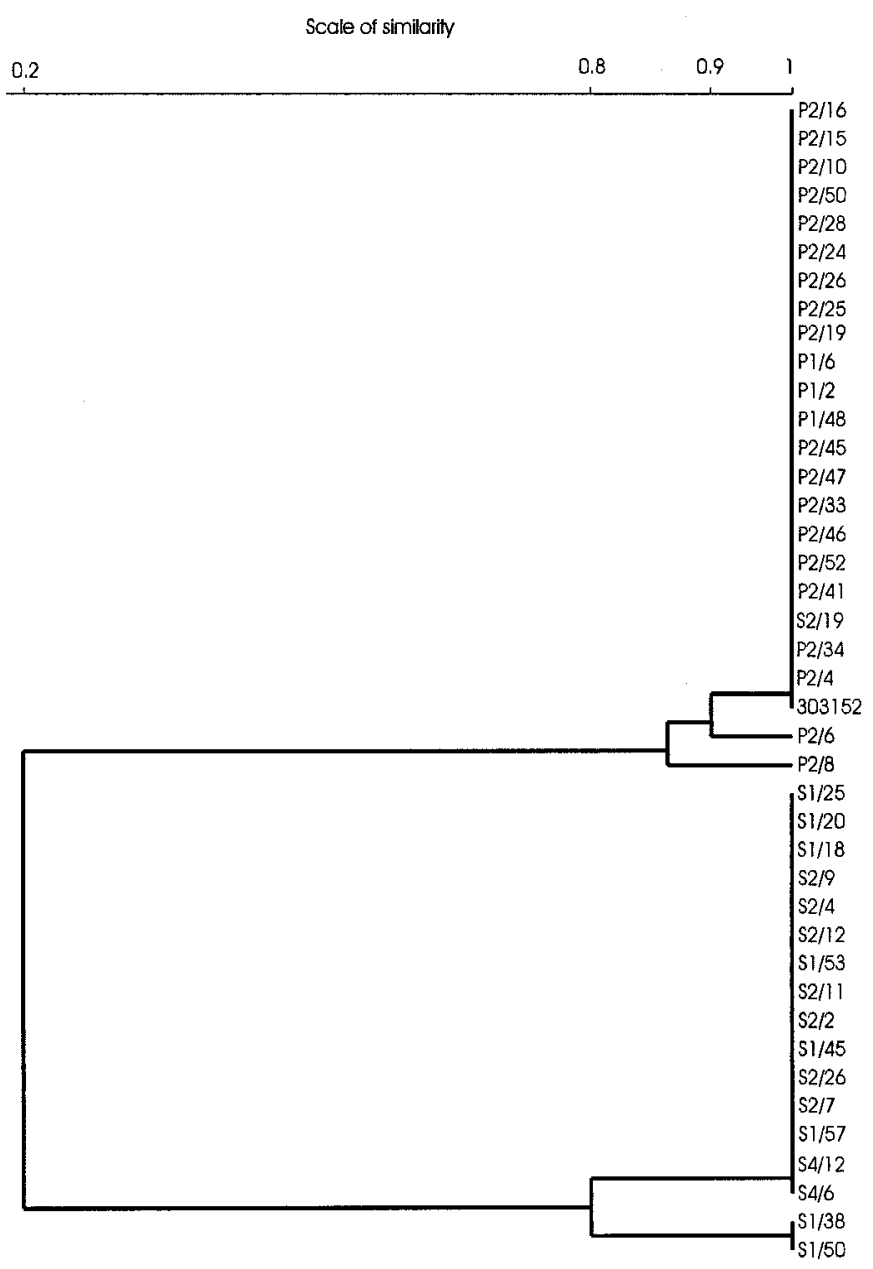

Fig. 3. Dendrogram depicting similarities in AT-rich DNA restriction fragment length polymorphisms (HaeIII digest) of isolates of Rhizoctonia solani from a field experiment in Côte d'Ivoire. Isolates coded ' $\mathrm{P}$ ' were obtained from plant material and those coded ' $\mathrm{S}$ ' originated from soil material. Distance and similarity analysis based on Gower's coefficient, unweighted pair group analysis clustering, cophenetic correlation coefficient $=0.99$. 
of various sizes. The second cluster, which comprised only soil isolates, was characterized by an abundance of aerial mycelium and the absence of sclerotia larger than $1 \mathrm{~mm}$. Both clusters showed between 62 and $100 \%$ similarity among isolates and were linked to each other at $60 \%$ similarity. Diversity in morphological characters was higher in plant than in soil isolates, but groups of isolates within the cluster of plant isolates could not be traced back to adjacent locations in specific research plots. Isolates within such groups of similar morphology appeared to be randomly distributed in the plots.

RFLP analysis of AT-DNA. Digestion of DNA with HaeIII generated two characteristic banding patterns (Fig. 2) in which 30 clearly visible, large molecular weight fragments of different sizes were identified for statistical analysis. Clustering of isolates resulted in a dendrogram depicting two major clusters $(\mathrm{CCC}=0.99)($ Fig. 3$)$. Most of the plant isolates and IMI303152 produced a RFLP consisting of 16 of the identified fragments ranging in size from approximately 1,710 to $4,910 \mathrm{bp}$. In two isolates, two additional fragments were observed. Apart from plant isolates, only one soil isolate (S2/19) that was also observed in the cluster of plant isolates based on morphological characters, shared this pattern. The remaining soil isolates produced a different RFLP pattern consisting of 14 characteristic fragments, only three of which were also found in the RFLP pattern exhibited by plant isolates (approximately 2,160, 2,420 , and 4,910 bp). Two soil isolates had two larger fragments in addition to this pattern.

Anastomosis testing. All isolates fused with the reference strain of AG-1 IA, IMI303152.

Pathogenicity testing. All but three isolates (P2/28, S1/57, and $\mathrm{S} 2 / 9$ ) caused disease symptoms on rice plants in experiment 1 , while only isolate $\mathrm{S} 2 / 7$ failed to cause infection in experiment 2 (Fig. 4). Plant isolates induced typical symptoms in the form of ellipsoid, grayish white spots with a brown margin, while lesions of soil isolates showed little contrast in color between the margin and the center. In experiment 1 , disease severity was generally low, with a population mean of $25 \mathrm{~mm}$ in comparison to $167 \mathrm{~mm}$ in experiment 2 . In both experiments, variance was relatively high. Analysis of ranks in experiment 1 revealed a significant difference in ranks among the three most virulent isolates (P2/46, P2/41, and $\mathrm{P} 1 / 6)$, the three isolates that did not cause symptoms (S1/57, S2/9, and $\mathrm{P} 2 / 28)$, and a mildly virulent isolate (P2/25) (data not shown). In experiment 2 , significant differences in ranks were only observed between the two most virulent isolates (P2/33 and $\mathrm{P} 2 / 50$ ) and the noninfectious isolate (S2/7) (data not shown). No correla- tion was observed between virulence and the origin of isolates in the experimental plots. Comparison of means of plant isolates versus soil isolates by a two-tailed $t$ test gave significantly lower means for soil isolates in both experiments $(P=0.001$ in experiment $1, P<$ 0.001 in experiment 2 ).

Detached leaf tests revealed that, with the exception of one soil isolate (S2/19), plant and soil isolates caused different symptoms. Plant isolates induced typical rice sheath blight symptoms of ellipsoidal shape with an initially greenish, but later gray, center and a dark brown margin. In contrast, soil isolates induced leaves to turn yellow and subsequently brown. Lesions with darker brown margins were also seen, but these lacked the pale center observed on leaves inoculated with plant isolates.

\section{DISCUSSION}

$R$. solani is generally considered to be a soilborne pathogen and, in rice, it is suggested that sclerotia surviving in the soil are the major source of infection (7). When sclerotia come into contact with a rice plant, they germinate and the emerging hyphae produce infection cushions on the exposed leaf sheath. Haustoria grow from these infection cushions, penetrate the host tissue, and typical green-gray, water-soaked lesions develop (8). Due to the soilborne nature of the disease, major emphasis was placed on the collection of soil samples in this study, because these were expected to produce data on the population structure and dynamics of the sheath blight pathogen from paddy rice plots grown with different crop rotations. However, characterization of soil and plant isolates showed that these were distinct populations, with plant isolates being present in the soil only in small numbers. Hence, the study of the soil populations of $R$. solani in this experiment with regard to the influence of crop rotations on the development of sheath blight proved to be less informative than anticipated.

Several quantitative studies have been conducted to investigate the influence of rotations on inoculum units of $R$. solani in the soil. Belmar et al. (2) compared fields in Texas with various rice rotations and found significantly more sclerotia in fields cropped with rice-soybean-rice than in fields with a pasture rotation. In contrast, Damicone et al. (7) described a negative linear relationship between density of sclerotia and the number of years cropped to soybean. Isolates obtained were not characterized in detail in either study, assuming that all sclerotia extracted from the soil were causal agents of disease in both rice and the alternative crop. Whether this was

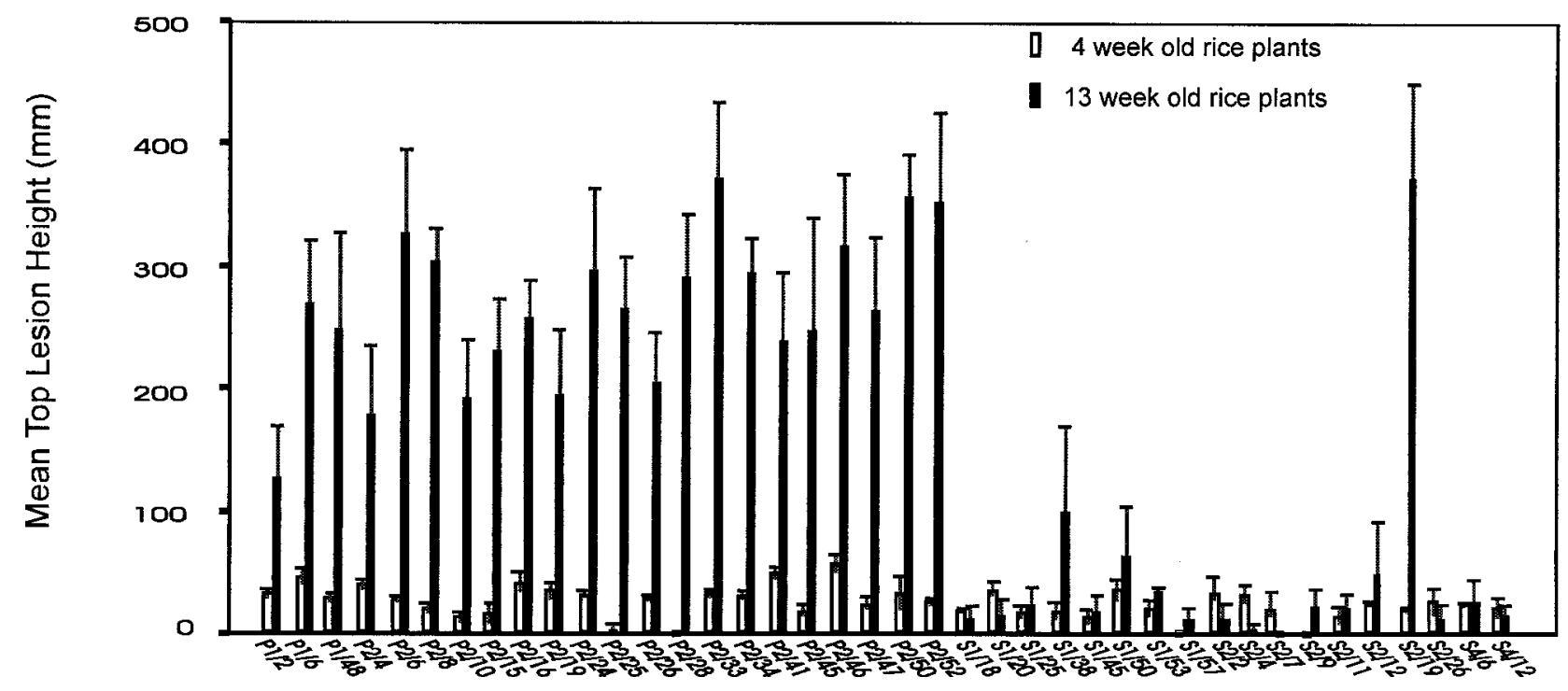

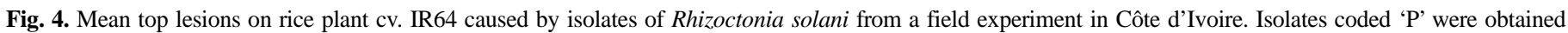
from plant material and those coded ' $\mathrm{S}$ ' originated from soil material. Measurements in millimeters from soil level to top lesion, means with standard errors. 
the case appears to be questionable, based on the results of this study. Unfortunately, soybean or weeds in the plots with fallow did not become infected with $R$. solani in this study, despite successful natural infection during the first and last rice crop in all experimental plots (S. Banniza, A. A. Sy, S. A. Simons, and M. Holderness, unpublished data). Although $R$. solani AG-1 has been isolated from plant species other than rice $(2,7,18,29,32,53)$, indicating that the alternative plant species in the rotations were potential host plants, it would have been interesting to see whether these isolates had been identical to those obtained from rice. However, lack of infection in soybean and weed plots might have been caused by nonconducive micro- and macroclimatic conditions due to differences in the canopy structure in comparison to a paddy rice plot.

Characterization of plant as well as soil isolates showed that none of the approaches used allowed groups of isolates to be correlated with a specific crop rotation. This suggests that populations of $R$. solani from plants and from the soil may have been indistinguishable in all plots throughout the experiment and were not influenced by different crop rotations. Whether the crop rotations had a quantitative effect on the soil population cannot be determined from this study, which was restricted to the qualitative characterization of $R$. solani. However, the limitation to three crop cycles with rotations of nonrice crops in plots that had been planted with rice for long periods prior to the experiment may have resulted in relatively stable populations that would only change after longer and repeated exposure to different host plants in long-term studies.

A major difference was discovered when comparing soil isolates with those isolated from sheath blight lesions. Both populations showed major differences in morphological characters and pathogenicity and had distinct AT-DNA RFLPs, with the exception of one soil isolate that had the same AT-DNA RFLP pattern as, was morphologically similar to, and was as virulent as, plant isolates. Pathogenicity testing under glasshouse conditions showed that soil isolates were able to infect young rice plants in particular, but disease symptoms differed slightly from those induced by plant isolates. Differences in disease severity on plants of the two age groups were expected, because it is known that young plants possess a certain degree of resistance to $R$. solani (33). Clear differences in virulence between soil and plant isolates became apparent on mature rice plants, suggesting that soil isolates seemed to be less aggressive. This might explain why these atypical symptoms were not observed on rice plants in the field and why these isolates were not recovered from plant material. The overlap in terms of plant and soil isolates might indicate that either the plant population represents a subpopulation of the soil or that some plant isolates temporarily spread into the soil without establishing themselves in large quantities. In the first case, one would expect to get Rhizoctonia spp. problems in any soil that contains the varied wild population; in the latter case, the pathogen has to be introduced from outside sources such as infected weeds. Infection through contaminated seed appears to be unlikely, because no infected seed was discovered in the samples.

In other studies, a high correlation has been found between overall inoculum density in the soil and sheath blight in rice $(2,7,19,34$, 39,42 ). Belmar et al. (2) found a highly significant linear relationship between inoculum density in the form of sclerotia in the soil and disease incidence. Similarly, Damicone et al. (7) found a significant relationship between preplanting density of sclerotia and incidence of sheath blight. Both studies strongly suggest that the disease is initiated through inoculum in the soil, even if the pathogenic isolates only represented a small proportion of the total soil population. However, both of these studies were conducted in fields in temperate or subtropical climates, which might have a major influence on the life cycle of the pathogen. Under tropical conditions in the Philippines, Butranu (3) observed that the number, viability, size, and weight of sclerotia of $R$. solani could not be correlated with rice sheath blight intensity. Differences in tropical and temperate or subtropical climate with regard to sclerotial densities were also reported by $\mathrm{Cu}$ et al. (6), who found far lower numbers of sclerotia under tropical conditions. They suggested that sclerotia might not be the primary source of inoculum, but that mycelium from plant residues could play a more important role. Soil isolates in this study were obtained from plant debris in the soil, but the majority of debris was not colonized by the same strains that had caused sheath blight of rice in the experimental plots. Assuming that the plant debris was mainly decaying rice plant material, it must have been infected with virulent plant isolates initially. The low recovery of the virulent isolate from the debris, however, suggests that this group of isolates possesses a lower fitness for survival in the soil in comparison to the soil isolates.

Anastomosis testing showed that soil isolates were able to anastomose with the reference strain of AG-1 IA but were distinct in all other characters. This suggests that the soil isolates may belong to another anastomosis group, strains of which are able to anastomose with AG-1. Anastomosis between isolates of different anastomosis groups has been observed in AG-2, -3, -6, -8, -11, and -BI (4). A bridging reaction with AG-1 was recently reported from an isolate identified as AG-6, which had been isolated from roots of Acacia tortilis (5), indicating that AG-1 might not be as genetically isolated as previously assumed. Considering the soilborne nature of the disease, it would be of interest to determine the relationship between the soil isolates obtained in this study and isolates of AG-1 and other AGs.

Considering the weak representation of plant isolates in the soil despite sheath blight infection in the plots, it must be assumed that the number of infection units in the soil is of minor importance in the development of the disease, while the rate of disease spread within the canopy seems to be more important in sheath blight epidemiology. If these results can be confirmed by further studies in other tropical rice systems, efforts to reduce or alter the soil population of $R$. solani, whether through soil solarization, the introduction of antagonistic fungi like Trichoderma and Aspergillus spp. (36), or other cultural or chemical practices, do not appear to be promising in preventing or controlling the disease. Effective plant protection is more likely to be achieved by preventing plantto-plant spread of the fungus through bacterization of seed (26), fungicide treatments, or the development of resistant varieties. For the development of simulation models in which the amount of primary (soilborne) inoculum is an important component of the model, the results of this study suggest that soilborne propagules of $R$. solani need to be qualitatively analyzed to determine the virulent infection units. Alternatively, as done by Savary et al. (38), primary inoculum should be derived from the number of primary foci of disease development.

The AT-DNA RFLP patterns observed for the plant isolates suggested that the population of plant isolates in the experimental plots was relatively homogeneous, but morphological characterization indicated that this population did not consist of a single clone. However, characters are often influenced by environmental factors (28). Therefore, it would be desirable to support nonclonality of this population by detailed anastomosis studies or molecular typing. Diversity of plant isolates of $R$. solani AG-1 in a paddy field was studied by Ogoshi and Ui (31), who identified 41 clones in a paddy field based on observations of perfect and imperfect fusion between isolates. Knowledge about the degree of diversity in the field population could clarify the question of the initial source of inoculum by comparing DNA fingerprints of rice isolates with those of isolates from the soil and other plant species in the rice system. In conjunction with information about the spatial and temporal development of the disease, fingerprints of rice isolates would also allow detailed epidemiological studies to be conducted, possibly providing new explanations for variation in disease incidence and spread in paddy rice fields. 


\section{ACKNOWLEDGMENTS}

This research was funded by the United Kingdom Department for International Development as part of the research project R5535 "Development of in vitro techniques for characterization of plant pathogenic strains of Rhizoctonia solani," commissioned through the Natural Resources Institute. The research was conducted under UK-MAFF licenses PHF 1490/748/93, PHF 1490/1243/114, and PHF 1490/1706 (11/95). We thank the Institute des Savannes, Bouaké, Côte d'Ivoire, for use of their experimental plots in this research.

\section{LITERATURE CITED}

1. Banniza, S., Rutherford, M. A., Bridge, P. D., Holderness, M., and Mordue, J. E. M. 1996. Biological characterization of Rhizoctonia solani in rice-based cropping systems. Pages 399-404 in: Proc. Brighton Crop Prot. Conf. Vol. 1. The British Crop Protection Council, Farnham, United Kingdom.

2. Belmar, S. B., Jones, R. K., and Starr, J. L. 1987. Influence of crop rotation on inoculum density of Rhizoctonia solani and sheath blight incidence in rice. Phytopathology 77:1138-1143.

3. Butranu, W. 1988. Carrying capacity of component crops on Rhizoctonia solani Kühn inoculum in relation to multiple cropping. M.Sc. thesis. University of the Philippines, Los Baños, Philippines.

4. Carling, D. E. 1996. Grouping in Rhizoctonia solani by hyphal anastomosis reaction. Pages 37-47 in: Rhizoctonia Species: Taxonomy, Molecular Biology, Ecology, Pathology and Disease Control. B. Sneh, S. Jabaji-Hare, S. Neate, and G. Dijst, eds. Kluwer Academic Publishers, Dordrecht, the Netherlands.

5. Carling, D. E., Meyer, L., and Brainard, K. A. 1996. Crater disease of wheat caused by Rhizoctonia solani AG-6. Plant Dis. 80:1429.

6. Cu, R. M., Mew, T. W., Cassman, K. G., and Teng, P. S. 1996. Effect of sheath blight on yield in tropical, intensive rice production systems. Plant Dis. 80:1103-1108.

7. Damicone, J. P., Patel, M. V., and Moore, W. F. 1993. Density of sclerotia of Rhizoctonia solani and incidence of sheath blight in rice fields in Mississippi. Plant Dis. 77:257-260.

8. Dodman, R. L., and Flentje, N. T. 1970. The mechanism and physiology of plant penetration by Rhizoctonia solani. Pages 149-160 in: Rhizoctonia solani, Biology and Pathology. J. R. Parmeter, ed. University of California Press, Berkley.

9. Egger, K. N. 1992. Analysis of fungal population structures using molecular techniques. Pages 193-208 in: The Fungal Community. Its Organization and Role in the Ecosystem. 2nd ed. G. C. Caroll and D. T. Wicklow, eds. Marcel Decker, Inc., New York.

10. Fisher, M., and Seefelder, S. 1995. Mitochondrial DNA and its inheritance in Pleurotus ostretus and P. pulmonarius. Bot. Acta 108: 334-343.

11. Freeman, S., Phom, M., and Rodruguez, R. J. 1993. Molecular genotyping of Colletotrichum species based on arbitrary primed PCR, A+T-rich DNA, and nuclear DNA analysis. Exp. Mycol. 17:309-322.

12. Gangopadhay, S., and Chakrabarti, N. K. 1982. Sheath blight on rice. Rev. Plant Pathol. 61:451-460.

13. Jabaji-Hare, S. H., Meller, Y., Gill, S., and Charest, P. M. 1990. Investigation of genetic relatedness among anastomosis groups of Rhizoctonia solani using cloned DNA probes. Can. J. Plant Pathol. 12:393-404.

14. Jin, T., and Horgen, P. A. 1994. Uniparental mitochondrial transmission in the cultivated button mushroom, Agaricus bisporus. Appl. Environ. Microbiol. 60:4456-4460.

15. Johnk, J. S., and Jones, R. K. 1992. Determination of whole-cell fatty acids in isolates of Rhizoctonia solani AG-1 IA. Phytopathology 82:68-72.

16. Johnk, J. S., and Jones, R. K. 1994. Comparison of whole-cell fatty acid compositions in intraspecific groups of Rhizoctonia solani AG-1. Phytopathology 84:271-275.

17. Jones, R. K., and Belmar, S. B. 1989. Characterization and pathogenicity of Rhizoctonia spp. isolated from rice, soybean, and other crops grown in rotation with rice in Texas. Plant Dis. 73:1004-1010.

18. Kardin, M. K., Kajiwara, T., and Muchsin, M. 1979. Weed species infected with Rhizoctonia solani. Pages 1-8 in: Masalah dan pengendalian penyakit tanaman pertanian Indonesia, M. A. Rifai, ed. Perhimpunan Fitopatologi Indonesia, Bogor, Indonesia.

19. Keinath, A. P. 1995. Relationships between inoculum density of Rhizoctonia solani, wirestem incidence and severity, and growth of cabbage. Phytopathology 85:1487-1492.

20. Kobayashi, T., Mew, T. W., and Hashiba, T. 1997. Relationship between incidence of rice sheath blight and primary inoculum in the Philippines: Mycelia in plant debris and sclerotia. Ann. Phytopathol. Soc. Jpn. 63:324-327.
21. Kuninaga, S., and Yokosawa, R. 1982. DNA base sequence homology in Rhizoctonia solani Kühn I. Genetic relatedness within anastomosis group 1. Ann. Phytopathol. Soc. Jpn. 48:659-667.

22. Liu, Z. L., and Sinclair, J. B. 1993. Differentiation of intraspecific groups within anastomosis group 1 of Rhizoctonia solani using ribosomal DNA internal transcribed spacer and isozyme comparison. Can. J. Plant Pathol. 15:272-280.

23. Mariott, A. C., Archer, S. A., and Buck, K. W. 1984. Mitochondrial DNA in Fusarium oxysporum is a 46.5 kilobase pair circular molecule. J. Gen. Microbiol. 130:3001-3008.

24. Martin, F. N. 1989. Maternal inheritance of mitochondrial DNA in sexual crosses of Pythium sylvaticum. Curr. Genet. 16:375-376.

25. Matsuyama, N., Moromizato, Z., Ogoshi, A., and Wakimoto, S. 1978. Grouping Rhizoctonia solani with non-specific esterase zymogram. Ann. Phytopathol. Soc. Jpn. 44:652-658.

26. Mew, T. W., and Rosales, A. M. 1986. Bacterization of rice plants for the control of sheath blight caused by Rhizoctonia solani. Phytopathology 76:1260-1264.

27. Milgroom, M. G., and Liparis, S. E. 1993. Maternal inheritance and diversity of mitochondrial DNA in the chestnut blight fungus, Chryphonectria parasitica. Phytopathology 83:563-567.

28. Mordue, J. E. M., Banniza, S., Bridge, P. D., Rutherford, M. A., and Holderness, M 1996. Integrated biochemical, cultural and numerical methods. Pages 87-98 in: Rhizoctonia Species: Taxonomy, Molecular Biology, Ecology, Pathology and Disease Control. B. Sneh, S. JabajiHare, S. Neate, and G. Dijst, eds. Kluwer Academic Publisher, Dordrecht, the Netherlands.

29. Nelson, B., Helms, T., Christianson, T., and Kural, I. 1996. Characterization and pathogenicity of Rhizoctonia from soybean. Plant Dis. 80:74-80.

30. Nemenyi, P. 1963. Distribution-Free Multiple Comparison. State University of New York, Downstate Medical Center, New York.

31. Ogoshi, A., and Ui, T. 1983. Diversity of clones within an anastomosis group of Rhizoctonia solani Kühn in a field. Ann. Phytopathol. Soc. Jpn. 49:239-245.

32. Onesiran, P. T. 1977. Comparison of Rhizoctonia solani isolates from web blight and basal canker of cowpea from soil. Plant Soil 46:135-143.

33. Ou, S. H. 1985. Rice Diseases. Commonwealth Mycological Institute, Richmond, Surrey, Great Britain.

34. Philipps, A. J. L. 1989. Relationship of Rhizoctonia solani inoculum density to incidence of hypocotyl rot of damping-off in dry beans. Can. J. Microbiol. 35:1132-1140.

35. Raeder, U., and Broda, P. 1985. Rapid preparation of DNA from filamentous fungi. Lett. Appl. Microbiol. 1:17-20.

36. Roy, A. K. 1996. Innovative methods to manage sheath blight of rice. J. Mycopathol. Res. 34:13-19.

37. Savary, S., Castilla, N. P., Elazegui, F. A., McLaren, C. G., Ynalvez, M. A., and Teng, P. S. 1995. Direct and indirect effects of nitrogen supply and disease source structure on rice sheath blight spread. Phytopathology 85:959-965.

38. Savary, S., Willocquet, L., and Teng, P. S. 1997. Modeling of sheath blight epidemics on rice tillers. Agric. Syst. 55:359-384.

39. Shahjahan, A. K. M., Fabeller, N., and Mew, T. W. 1990. Effect of crop management practices on the sclerotia dynamics of Rhizoctonia solani in upland rice. Bangladesh J. Plant Pathol. 6:19-23.

40. Sherwood, R. T. 1969. Morphology and pathology of four anastomosis groups of Thanatephorus cucumeris. Phytopathology 59:1924-1929.

41. Sneath, P. H. A., and Sokal, R. R. 1973. Numerical Taxonomy. W. H. Freeman and Company, San Francisco.

42. Sneh, B., Katan, J., Henis, Y., and Wahl, I. 1966. Identification of Rhizoctonia Species. The American Phytopathological Society, St. Paul, MN.

43. Specht, C. A., Novotny, C. P., and Ullrich, R. C. 1992. Mitochondrial DNA of Schizophyllum commune: Restriction map, genetic map, and mode of inheritance. Curr. Genet. 22:129-134.

44. Taylor, J. W. 1986. Fungal evolutionary biology and mitochondrial DNA. Exp. Mycol. 10:259-269.

45. Typas, M. A., Griffen, A. M., Bainbridge, B. W., and Heale, J. B. 1992. Restriction fragment length polymorphisms in mitochondrial DNA and ribosomal RNA gene complexes as an aid to the characterization of species and sub-species populations in the genus Verticillium. FEMS (Fed. Eur. Microbiol. Soc.) Microbiol. Lett. 95:157-162.

46. Typas, M. A., Mavridu, A., and Kouvelis, V. N. 1998. Mitochondrial DNA differences provide maximum intraspecific polymorphism in the entomopathogenic fungi Verticillium lecanii and Metarhizium anisopliae, and allow isolate detection/identification. Pages 227-237 in: Molecular Variability of Fungal Pathogens. P. Bridge, Y. Conteaudier, and J. Clarkson., eds. CABI Bioscience, Wallingford, United Kingdom.

47. Vijayan, M., and Nair, C. M. 1985. Anastomosis grouping of isolates of 
Rhizoctonia solani Kühn (Thanatephorus cucumeris (Frank) Donk) causing sheath blight of rice. Curr. Sci. 54:289-291.

48. Vilgalys, R., and González, D. 1990. Ribosomal DNA restriction length polymorphisms in Rhizoctonia solani. Phytopathology 80:151-158.

49. Vilgalys, R., and Hester, M. 1990. Rapid genetic identification and mapping of enzymatically amplified ribosomal DNA from several Cryptococcus species. J. Bacteriol. 172:4238-4246.

50. Weinhold, A. R. 1977. Population of Rhizoctonia solani in agricultural soils determined by a screening procedure. Phytopathology 67:566-569.

51. Whittaker, S. L., Assinder, S. J., and Shaw, D. S. 1996. Inheritance of streptomycin and chloramphenicol resistance in Phytophthora infestans:
Evidence for co-segregation of mitochondrial DNA and streptomycin resistance. Mycol. Res. 100:87-92.

52. Wingfield, B. D., Harrington, T. C., and Steimel, J. 1996. A simplified method for detection of mitochondrial DNA polymorphisms. Fungal Genet. Newsl. 43:56-60.

53. Yang, X. B., Snow, J. P., and Berggren, G. T. 1990. Analysis of epidemics of Rhizoctonia aerial blight of soybean in Louisiana. Phytopathology 80:386-392.

54. Zuber, M., and Manibhushanrao, K. 1982. Studies on comparative gel electrophoretic patterns of proteins and enzymes from isolates of Rhizoctonia solani causing sheath blight disease in rice. Can. J. Microbiol. 28:762-771. 